\title{
How much of the interannual variability of East Asian summer rainfall is forced by SST?
}

\author{
Chao $\mathrm{He}^{1,2} \cdot \mathrm{Bo} \mathrm{Wu}^{2} \cdot$ Chunhui $\mathrm{Li}^{1} \cdot$ Ailan $\mathrm{Lin}^{1} \cdot$ Dejun $\mathrm{Gu}^{1} \cdot$ Bin $\mathrm{Zheng}^{1} \cdot$ \\ Tianjun Zhou ${ }^{2,3}$
}

Received: 25 May 2015 / Accepted: 24 September 2015 / Published online: 26 October 2015

(C) The Author(s) 2015. This article is published with open access at Springerlink.com

\begin{abstract}
It is widely accepted that the interannual variability of East Asian summer rainfall is forced by sea surface temperature (SST), and SST anomalies are widely used as predictors of East Asian summer rainfall. But it is still not very clear what percentage of the interannual rainfall variability is contributed by SST anomalies. In this study, Atmospheric general circulation model simulations forced by observed interannual varying SST are compared with those forced by the fixed annual cycle of SST climatology, and their ratios of interannual variance (IAV) are analyzed. The output of 12 models from the 5th Phase of Coupled Model Intercomparison Project (CMIP5) are adopted, and idealized experiments are done by Community Atmosphere Model version 4 (CAM4). Both the multi-model median of CMIP5 models and CAM4 experiments show that only about $18 \%$ of the IAV of rainfall over East Asian land (EAL) is explained by SST, which is significantly lower than the tropical western Pacific, but comparable to the mid-latitude western Pacific. There is no significant difference between the southern part and the northern part of EAL in the percentages of SST contribution. The remote SST anomalies regulates rainfall over EAL probably by
\end{abstract}

Chao $\mathrm{He}$

hechao@mail.iap.ac.cn

Tianjun Zhou

zhoutj@lasg.iap.ac.cn

1 Institute of Tropical and Marine Meteorology (ITMM), China Meteorological Administration (CMA), No. 6, Fujin Road, Guangzhou 510080, China

2 LASG, Institute of Atmospheric Physics (IAP), Chinese Academy of Sciences (CAS), P.O. Box 9804, Beijing 100029, China

3 Joint Center for Global Change Studies (JCGCS), Beijing, China modulating the horizontal water vapor transport rather than the vertical motion, since the horizontal water vapor transport into EAL is strongly modulated by SST but the vertical motion over EAL is not. Previous studies argued about the relative importance of tropical Indian Ocean and tropical Pacific Ocean to East Asian summer rainfall anomalies. Our idealized experiments performed by CAM4 suggest that the contributions from these two ocean basins are comparable to each other, both of which account for approximately $6 \%$ of the total IAV of rainfall over EAL.

Keywords Rainfall $\cdot$ Interannual variance $\cdot$ Sea surface temperature

\section{Introduction}

Summer is the rainy season for East Asia which is affected by the monsoon. The interannual variability of the East Asian summer rainfall is regulated by multiple factors, such as the atmospheric internal dynamics ( $\mathrm{Lu}$ et al. 2006; Kosaka et al. 2012; Song et al. 2013), the sea surface temperature (SST) forcing (Chang et al. 2000; Wang et al. 2013; Zuo et al. 2013), and land-atmosphere interaction (Zhang et al. 2011; Duan et al. 2012; Li et al. 2015). Among the factors affecting East Asian summer rainfall, it is widely accepted that the most important source of predictability originates from the SST anomalies (Lin et al. 2012; Yim et al. 2014; Wang et al. 2015), especially the SST anomalies (SSTA) directly or indirectly associated with El Nino-Southern Oscillation (ENSO) (Yang et al. 2008, 2012; Zuo et al. 2013; Wang et al. 2013). SST anomalies over some key regions are widely used as predictors for East Asian summer rainfall anomaly (Wu et al. 2009; Cao et al. 2013; Wang et al. 2013). 
The SST anomalies affect East Asian summer rainfall anomalies by modulating water vapor transport associated with anomalous circulation (Zhang 2001; Zhou and Yu 2005; Li et al. 2014). As a result of warm SST anomalies over tropical Indian Ocean (Li et al. 2008; Xie et al. 2009; Wu et al. 2010) or cold SST anomalies over equatorial central Pacific Ocean (Wang et al. 2013; Xiang et al. 2013), an anomalous anticyclone forms over the western North Pacific. By modulating horizontal water vapor transport, this anomalous anticyclone induces excessive rainfall over the Yangtze River Valley, and deficient rainfall over South China and North China (Chang et al. 2000; Zhang 2001; Zhou and Yu 2005; Li et al. 2014). Tropical Indian Ocean (TIO) and Tropical Pacific Ocean (TPO) are both claimed as key regions responsible for summer rainfall anomalies over East Asia. Some previous studies emphasized the importance of TIO (Xie et al. 2009; Kosaka et al. 2013) but others argued the TPO is more important to East Asian summer rainfall anomalies (Wang et al. 2013; Xiang et al. 2013).

Despite its crucial role on the precipitation variability in the tropics, the impact of SST on rainfall variability is much limited in the extra-tropics, especially in summer (Koster et al. 2000; Conil et al. 2007; Sun and Wang 2014). Studies focused on drought have revealed that the drought events are stochastically generated over most mid-latitude land regions, while SST only plays a secondary role (Ferguson et al. 2010; Stevenson et al. 2015). However, most of these studies are focused on North America or from a global perspective, and it is still unclear to what extent is the interannual variability of East Asian summer rainfall forced by SST.

Almost all of the previous studies which quantitatively assessed the potential predictability of climate are based on only one model (e.g., Conil et al. 2007; Koster et al. 2000; Sun and Wang 2014; Stevenson et al. 2015). It is inevitable that their results may be model dependent (Conil et al. 2007). Recently, the 5th phase of Coupled Model Intercomparison Project (CMIP5; Taylor et al. 2012) has released a large set of simulations performed by multiple models, motivating us to quantitatively assess the contribution of SST to East Asia summer rainfall variability under the multi-model framework. The following two scientific questions will be addressed in this study: (1) To what extent is the interannual variability of East Asian summer rainfall forced by SST? How does it differ from the surrounding western Pacific Ocean? (2) Which oceanic region contributes more to the East Asian summer rainfall variability, TIO or TPO?

The rest of this paper is organized as follows. Section 2 describes the models, data and the methods. A brief model evaluation against observation is presented in Sect. 3. A comparison of CMIP5-AGCMs between the fixed SST simulation and interannual-varying SST simulation is presented in Sect. 4. Furthermore, idealized experiments performed by Community Atmospheric Model Version 4 (CAM4) are analyzed in Sect. 5. Finally, the conclusion and discussion are presented in Sect. 6.

\section{Models, data and methods}

Multiple kinds of simulations by a large number of models were collected by CMIP5 (Taylor et al. 2012). The model simulations provided by CMIP5 include the AMIP simulation forced by observed interannual varying SST from 1979 to 2008, and the SSTClim simulation forced by fixed annual cycle of SST derived from the climatology of preindustrial control run. The SSTClim simulation are run for 30 years, and the monthly output of models which contain both AMIP and SSTClim simulations are analyzed in this study. The interannual climate variability in AMIP simulations are modulated by both SST forcing and Non-SST factors, such as atmospheric internal dynamics and landatmosphere coupled processes. In contrast, the interannual climate variability in SSTClim simulation is driven by only Non-SST factors. A comparison between AMIP and SSTClim simulations helps us to understand how much of the interannual variability is forced by SST. There are 12 models which contain both AMIP and SSTClim simulations among all the CMIP5 models, and these 12 models are selected for analyses (Table 1). Multi-model Median (MMM) is calculated as the median of the 12 models, and the inter-model spread is shown as the standard deviation of the 12 models. The median of the models is less affected by outliers than the multi-model mean value (Gleckler et al. 2008).

It is worth noting that the fixed SST annual cycle in SSTClim simulation is derived from the pre-industrial control run, which is not exactly the same as the climatology in the AMIP run. To corroborate the results obtained from CMIP5 models, additional experiments are performed by CAM4 (Neale et al. 2010). The CAM4 experiments are performed under a finite volume dynamic core, which is equivalent to a horizontal resolution of $1.9^{\circ} \times 2.5^{\circ}$. The control simulation (CTL) is forced by interannual-varying monthly SST from 1900 to 2000 (Hurrell et al. 2008), similar to the AMIP simulation in CMIP5. Besides, F_SST experiment is performed by forcing CAM4 with the climatological annual cycle of SST which exactly equals the SST climatology in CTL run. The F_SST experiment is also run for 101 years, and the last 100 years of CTL and F_SST experiments are selected for analysis.

To investigate the relative importance of TIO SST and TPO SST to East Asian summer rainfall, another two experiments named F_TIO and F_TPO are done with 
Table 1 Information about the 12 CMIP5 models in this study

\begin{tabular}{lll}
\hline ID & Model name & Modeling group \\
\hline 1 & BNU-ESM & College of Global Change and Earth System Science, Beijing Normal University (GCESS) \\
2 & bcc-csm1.1 & Beijing Climate Center, China Meteorological Administration (BCC) \\
3 & CCSM4 & National Center for Atmospheric Research (NCAR) \\
4 & CSIRO-Mk3.6.0 & Commonwealth Scientific and Industrial Research Organization in collaboration with Queensland Climate Change Cen- \\
& & tre of Excellence (CSIRO-QCCCE) \\
5 & FGOALS-s2 & LASG, Institute of Atmospheric Physics, Chinese Academy of Sciences (LASG-IAP) \\
6 & GFDL-CM3 & NOAA Geophysical Fluid Dynamics Laboratory (NOAA GFDL) \\
7 & inmcm4 & Institute for Numerical Mathematics (INM) \\
8 & IPSL-CM5A-LR & Institut Pierre-Simon Laplace (IPSL) \\
9 & MIROC5 & Japan Agency for Marine-Earth Science and Technology, Atmosphere and Ocean Research Institute (The University of \\
& & Tokyo), and National Institute for Environmental Studies (MIROC) \\
10 & MPI-ESM-LR & Max-Planck-Institut für Meteorologie (Max Planck Institute for Meteorology) (MPI-M) \\
11 & MPI-ESM-MR & \\
12 & MRI-CGCM3 & Meteorological Research Institute (MRI) \\
\hline
\end{tabular}

The IDs in the leftmost column are used to indicate the model names in Figs. $2 \mathrm{~b}$ and $4 \mathrm{~b}$

CAM4. The only difference between F_TIO and CTL is that the SST over TIO $\left(30^{\circ} \mathrm{S}-30^{\circ} \mathrm{N}, 40^{\circ}-110^{\circ} \mathrm{E}\right)$ is fixed as the climatological annual cycle in F_TIO run. The only difference between F_TPO and CTL is that the SST over TPO $\left(30^{\circ} \mathrm{S}-30^{\circ} \mathrm{N}, 150^{\circ} \mathrm{E}-90^{\circ} \mathrm{W}\right)$ is fixed as the climatological annual cycle. The F_TIO and F_TPO experiments are also run for 101 years and the last 100 years are selected for analysis.

Given the uncertainty in precipitation observation (Collins et al. 2013), two monthly precipitation datasets are adopted in the model evaluation part in Sect. 3. They include the version-2 Global Precipitation Climatology Project (GPCP) data (Adler et al. 2003), and the CPC Merged Analysis of Precipitation (CMAP) data (Xie and Arkin 1997). For all the model outputs and observational data, monthly values for June, July and August (JJA) of each year are averaged into seasonal mean before further analyses.

Two metrics were adopted by previous studies to measure the amplitude of interannual variability, including standard deviation (Lu and Fu 2010; Fan et al. 2014; Sun and Wang 2014) and variance (Kumar and Hoerling 1995; Koster et al. 2000; Ferguson et al. 2010; Stevenson et al. 2015). In this study, we measure the interannual variability in terms of Interannual Variance (IAV) calculated as the variance of the 8-year high-pass filtered time series. The variance of the sum of two independent random variables equals the sum of their variance, but such law doesn't apply to standard deviation. This is why we choose to use variance rather than standard deviation.

The total IAV in reality (IAV(Tot)) is contributed by SST-forced component (IAV(SST)) and Non-SST factors (IAV(Non)). Supposing the SST forced variability is independent from the Non-SST induced variability, the relationship $\operatorname{IAV}($ Tot $)=\operatorname{IAV}(\mathrm{SST})+\operatorname{IAV}($ Non) holds. For CMIP5 models, The IAV in AMIP simulation (IAV(AMIP)) is an estimation of IAV(Tot), and the IAV in SSTClim simulation (IAV(SSTClim)) is an estimation of IAV(Non). Therefore, the SST contribution to the total IAV can be estimated as 1-IAV(SSTClim)/IAV(AMIP) for CMIP5 models. The fraction of SST contribution for each model is calculated, and then the MMM is obtained. For CAM4 experiments, the IAV in CTL and the F_SST experiments are the estimations of IAV(Tot) and IAV(Non), respectively. The SST contribution to the total IAV can be estimated as 1-IAV(F_SST)/IAV(CTL) in CAM4.

The relative contributions of SST forcing from TIO and TPO can be estimated by comparing F_TIO and F_TPO experiments with CTL experiment of CAM4. The contribution of TIO SST to the total IAV can be estimated as 1-IAV(F_TIO)/IAV(CTL), since the interannual variability in F_TIO experiment is induced by all the other factors except the TIO SST forcing. Similarly, the contribution of TPO SST can be estimated as 1-IAV(F_TPO)/IAV(CTL), since the interannual variability in F_TPO experiment is induced by all the other factors except the TPO SST forcing.

\section{Model evaluation on the IAV of summer rainfall}

The simulated IAV of rainfall is evaluated against observation in this section. Given the uncertainty in observation (Collins et al. 2013; He and Zhou 2015), we use two precipitation datasets, including GPCP and CMAP. As seen in both GPCP and CMAP (Fig. 1), the IAV of JJA 


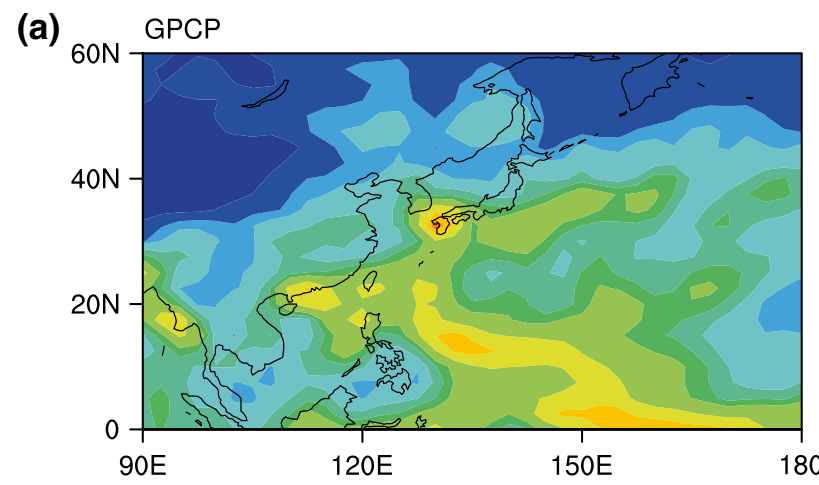

(b)

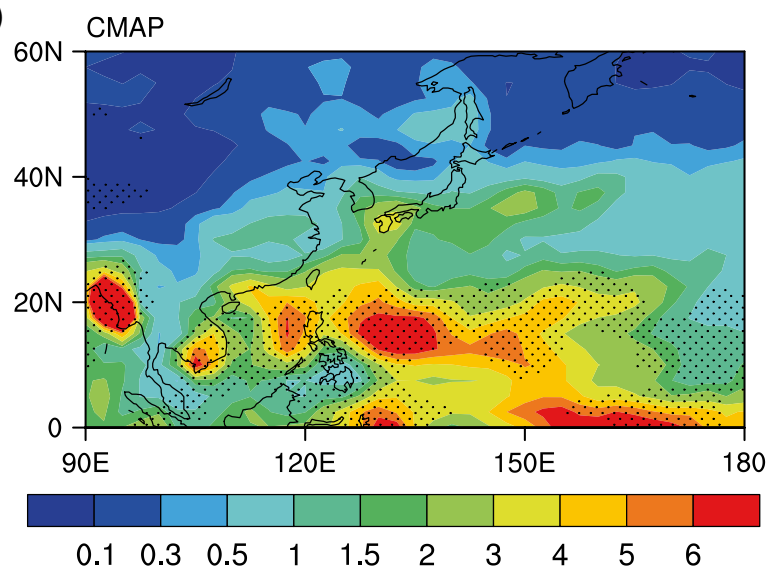

Fig. 1 Observed climatology of the IAV for JJA mean precipitation rate [unit:(mm/day $)^{2}$ ]. a, b are derived from GPCP and CMAP datasets, respectively. The black dotted regions in $\mathbf{b}$ indicates that the IAV estimated by CMAP is 1.5 times greater than GPCP

precipitation is higher in the tropics than in mid-latitudes. The magnitude of IAV is consistent between these two datasets north of $20^{\circ} \mathrm{N}$, but differs a lot south of $20^{\circ} \mathrm{N}$. For most areas between the equator and $20^{\circ} \mathrm{N}$, the IAV of precipitation in CMAP is $50 \%$ higher than in GPCP. In this study, we do not intend to conclude which dataset is superior to the other, but we should bear in mind that great observational uncertainty exists not only in the mean state of seasonal rainfall (He and Zhou 2015) but also in its IAV over tropical western Pacific.

The general spatial pattern of IAV in observation data is captured by the MMM of AMIP simulation (IAV(AMIP)), including the generally higher IAV in the tropics than in mid-latitudes, and the local maximum over the eastern side of the Philippines (Fig. 2a). The spatial pattern of MMM is closer to CMAP than GPCP, since the IAV in the MMM is much higher than GPCP but comparable with CMAP in the tropics (see Fig. 1). Compared with CMAP, The MMM estimated IAV is higher over most of the East Asian land regions, South China Sea and eastern Bay of Bengal, but lower over equatorial central Pacific.

Given the magnitudes of IAV in precipitation are different among East Asian land (EAL), tropical western Pacific

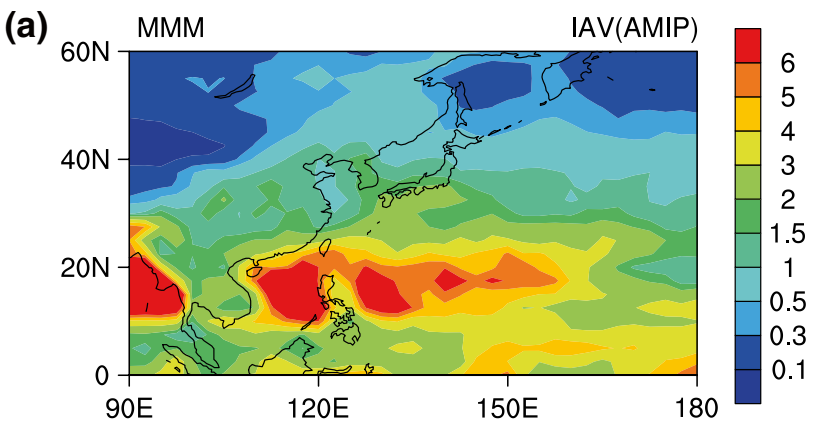

(b)

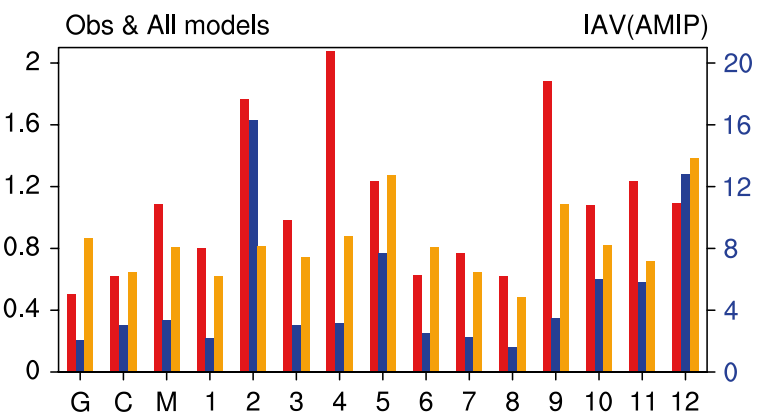

Fig. 2 a The multi-model median (MMM) of the IAV for JJA precipitation in AMIP simulations (IAV(AMIP)). b Regional averaged IAV for GPCP (G), CMAP (C), Multi-model median (M) and individual models (1-12). Red bars indicate the East Asian Land average (land regions within $\left.20^{\circ}-60^{\circ} \mathrm{N}, 90^{\circ}-150^{\circ} \mathrm{E}\right)$, blue bars indicate the Tropical West Pacific average (oceanic regions within $0^{\circ}-30^{\circ} \mathrm{N}, 130^{\circ}-180^{\circ} \mathrm{E}$ ), and orange bars indicate the Mid-latitude West Pacific average (oceanic regions within $30^{\circ}-60^{\circ} \mathrm{N}, 130^{\circ}-180^{\circ} \mathrm{E}$ ). The legend on the left (right) $y$-axis are for the red and orange bars (blue bars)

(TWP) and mid-latitude Pacific (MWP), the regional averaged IAVs are shown separately for these three regions as bar charts in Fig. 2b. The MMM estimated regional averaged IAVs for the EAL and TWP are higher than both GPCP and CMAP, but close to the observations over MWP. Although the IAV for the TWP is overestimated for about four times in bcc-csm1.1 and MRI-CGCM3 (denoted as " 2 " and "12" in Fig. 2b), the MMM is not substantially misled by these outlier models, suggesting the superiority of multi-model median to multi-model average (Gleckler et al. 2008). We will use all of the 12 models to construct the MMM in the following section for three reasons. First, the multi-model median is not sensitive to outliers. Second, outliers in climatology simulation are not necessarily outliers in other aspects (this will be stated in the following section). Third, excluding outlier models may result in a too small sample size.

\section{SST contribution estimated by CMIP5 models}

The spatial pattern of IAV for rainfall in the SSTClim simulation of CMIP5 MMM is shown in Fig. 3a, which is an 
(a)

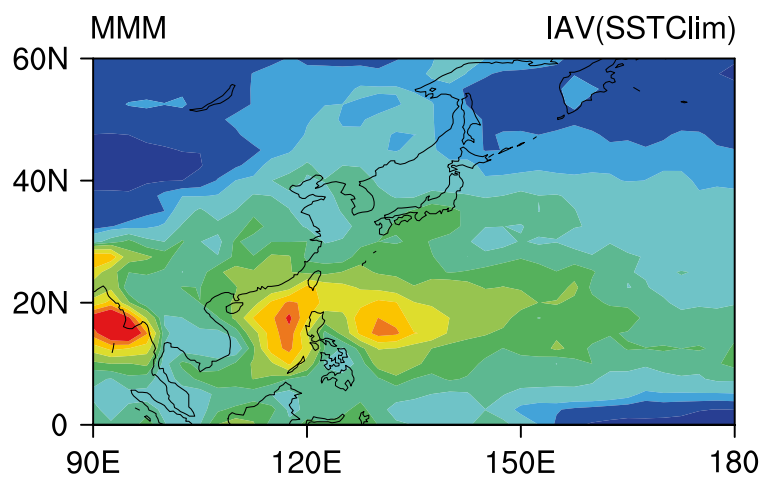

(b)

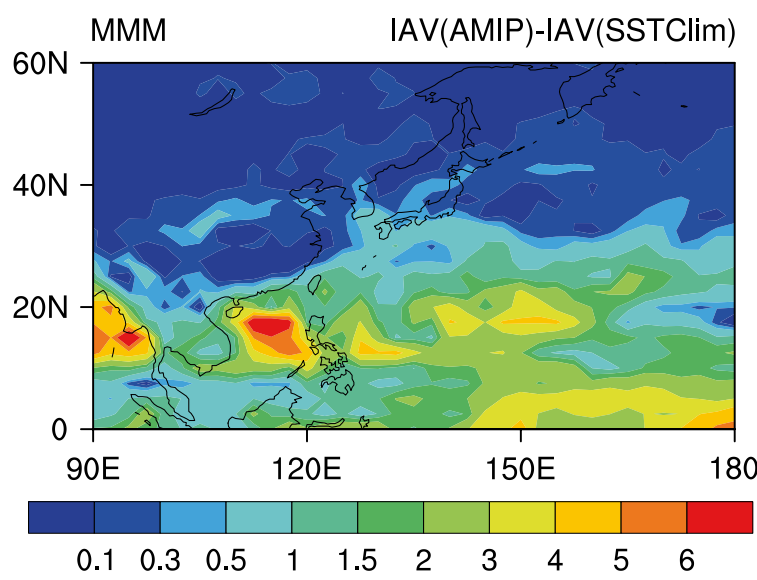

Fig. 3 a The IAV of precipitation contributed by Non-SST factors, as estimated by the SSTClim simulation (IAV(SSTClim)) of CMIP5 multi-models median. b The IAV of precipitation contributed by SST, as estimated by the CMIP5 multi-model median of difference between AMIP and SSTClim experiments, i.e., IAV(AMIP)IAV(SSTClim)

estimation of the rainfall variability induced by Non-SST factors. The difference of IAV between AMIP and SSTClim simulations is shown in Fig. 3b, which is an estimation of the SST forced component of summer rainfall variability. The SST forced variance is comparable to NonSST induced variance in most of the tropics, but is smaller than the Non-SST induced IAV in mid-latitudes and EAL regions. Over EAL, the Non-SST induced IAV decreases smoothly from the southeast to the northwest, which generally follows the pattern of climatological IAV (see Figs. 1, 2a). Over the western Pacific Ocean, the SST forced IAV falls sharply from the south to the north along $30^{\circ} \mathrm{N}$ (Fig. 3b). Over East Asia, the SST forced component is characterized by a sharp land-sea contrast along the southern coast. There is no obvious difference in the magnitude of SST forced IAV between southeast China and the inland dry regions (Fig. 3b), while the Non-SST induced IAV is higher in the southern part than the northern part (Fig. 3a).

Figure 4a shows the spatial pattern of 1-IAV(SSTClim)/ IAV(AMIP) for summer rainfall as estimated by CMIP5

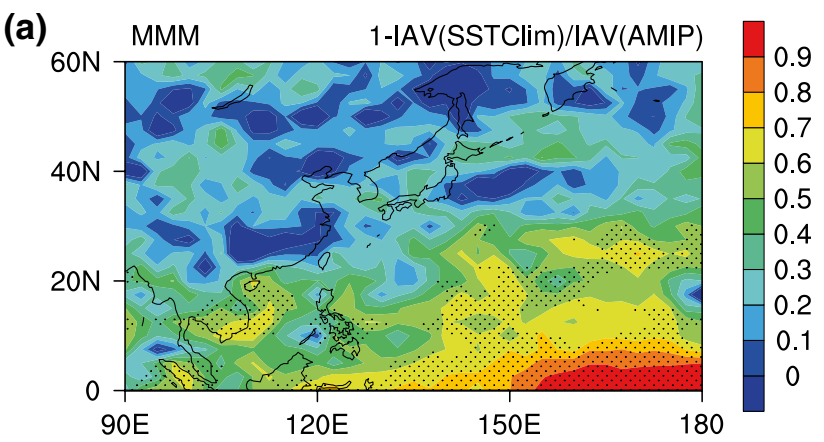

(b)

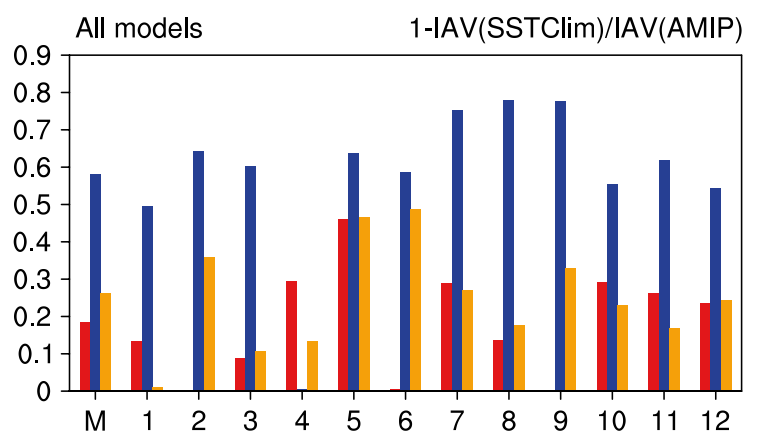

Fig. 4 a The fraction of SST contribution to the total IAV of precipitation, as estimated by the CMIP5 multi-model median (MMM) based on SSTClim and AMIP simulations, i.e., 1-IAV(SSTClim)/ IAV(AMIP). The black dotted regions indicate the difference in the IAV between SSTClim and AMIP simulations is significant at the $95 \%$ confidence level. b The regional averaged values of 1-IAV(SSTClim)/IAV(AMIP) for MMM (M) and the individual models (1-12). The red, blue and orange bars are the regional averages for East Asian land, tropical western Pacific, and mid-latitude western Pacific, respectively

MMM, which is an estimation of the percentage of SST contribution to total IAV. The contribution of SST decreases sharply from the south to the north along the southeastern coast of China. Little difference is seen between southern part of East Asia and northern part of East Asia, consistent with previous studies who showed no substantial difference between northern China and southern China in summer whereas higher contribution from SST to southern China in winter (Wu et al. 2003, their Fig. 6). The percentage of SST contribution is estimated to be below 0 for some regions over EAL and MWP, which may be induced by noise related to limited sample size (only 12 models) and the available data length (only 30 years). The percentage of SST contribution to the IAV of rainfall over EAL is much smaller than TWP but characterized by similar magnitude as MWP. The value of 1-IAV(SSTClim)/IAV(AMIP) is above 0.4 for most of the TWP, especially for the equatorial regions within $150^{\circ}-180^{\circ} \mathrm{E}$ where it exceeds $80 \%$. The difference between IAV(SSTClim) and IAV(AMIP) is significant at the $95 \%$ confidence level over most of tropical oceans but not in EAL and MWP. 
Given to noise seen in the spatial pattern, it may be useless to discuss the fraction of SST-contribution at a single grid point or over a small area. Only the regional average over large areas are meaningful. The EAL and MWP regions are large enough to contain several negative centers and several positive centers with relatively large values, and the regional averaging over EAL and MWP regions could effectively suppress the noise. The regional averaged values of 1-IAV(SSTClim)/IAV(AMIP) for MMM and all the 12 models are shown in Fig. 4b, which are estimations of the percentages of SST contribution to the total IAV over EAL, TWP and MWP, respectively. The MMM estimated percentages of contribution by SST are $18.4 \%$ for EAL, $58.2 \%$ for TWP, and $26.2 \%$ for MWP. Except for CSIRO-Mk3.6.0 (denoted as "4" in Fig. 4b), all of the other models are consistent that the fractions of SST contribution over EAL and MWP are smaller than TWP, and most of the individual models agree that the fractions of SST contribution to EAL and MWP are comparable with each other. In brief, the SST-contributed fractions to total IAV in summer rainfall are comparable between EAL and MWP, which are far lower than the TWP.

For the two outlier models bcc-csm1.1 and MRICGCM3 in the simulation of climatology, bcc-csm1.1 (denoted as "2" in Fig. 4b) seems an outlier again in terms of negative SST contribution over EAL, but it is close to the MMM over the TWP and MWP (Fig. 4b). The SSTcontributed fractions estimated by MRI-CGCM3 are close to the MMM for all the three regions (denoted as "12" in Fig. 4b). Therefore, it is not reasonable to exclude a model simply because it is an outlier in a certain aspect of the climatology simulation, since it is not necessarily outliers in other aspects.

How does the interannual SST variability modulate the interannual rainfall variability? Previous studies suggested the importance of horizontal water vapor transport (Zhang 2001; Zhou and Yu 2005; Li et al. 2012, 2014). Since the water vapor transport at $850 \mathrm{hPa}$ is proximately proportional to the vertically integrated water vapor transport (Zhou and Yu 2005; Wang and Chen 2012), we examined the values of 1-IAV(SSTClim)/IAV(AMIP) for $850 \mathrm{hPa}$ water vapor transport by zonal and meridional winds in Fig. 5a-d. Since vertical motion in the mid-troposphere is another direct factor in regulating the rainfall, we also examined the value of 1-IAV(SSTClim)/IAV(AMIP) for vertical velocity at $500 \mathrm{hPa}$ (Fig. $5 \mathrm{e}-\mathrm{f}$ ).

The fraction of SST contribution to horizontal water vapor transport shares similar spatial pattern as that of precipitation. Slightly higher contribution from SST is seen for horizontal water vapor transport than precipitation over EAL, and the difference between IAV(SSTClim) and IAV(AMIP) is significant at the $95 \%$ confidence level over a large part of EAL and MWP within $20^{\circ} \mathrm{N}-40^{\circ} \mathrm{N}$ (Fig. 5a, c). As seen in the regional averages, the SST contributions to the total IAV of zonal water vapor transport are 44.8, 79.4, and $40.3 \%$ for EAL, TWP and MWP, respectively (Fig. 5b, d), and the contributions of SST to the meridional water vapor transport are $34.4,50.0$ and $24.4 \%$ for EAL, TWP and MWP, respectively. The contributions from SST forcing are comparable for the EAL and MWP, which are much lower than the TWP.

In contrast to the horizontal water vapor transport, the fraction of SST-contribution to vertical velocity at $500 \mathrm{hPa}$ is approximately 0 over EAL, which explains why the SST contribution to rainfall is lower than the SST contribution to water vapor transport. There is a sharp decrease in the percentage of SST contribution from the south to the north along the southern coast of East Asia (Fig. 5e). The MME estimated regional average of 1-IAV(SSTClim)/ IAV(AMIP) is $-4.0 \%$ for EAL and $5.3 \%$ for MWP, both of which are approximately 0 (Fig. 5f), suggesting the IAV for the vertical velocity is not affected by the SST over EAL and MWP. As proposed by Johnson and Xie (2010), the deep convection in tropical oceans are strongly modulated by local SST relative to the tropical averaged SST, but this law doesn't apply to land regions and mid-latitude oceans. This may explain why the SST contribution is far larger for TWP than over EAL and MWP.

The above evidences in Fig. 5 suggest that the SST impacts the IAV of rainfall over EAL and MWP by modulating the horizontal water vapor transport, rather than modulating the vertical velocity. Many previous studies revealed the role of horizontal water vapor transport in connecting the tropical SST and East Asian rainfall (e.g., Zhou and $\mathrm{Yu}$ 2005; Li et al. 2012, 2014), but few studies documented the relationship between vertical motion on EAL with the SST. Therefore, our results are consistent with previous studies.

In short, the above results based on CMIP5 models suggest two points. First, the percentage of SST contribution to the interannual variability of summer rainfall is much lower for the EAL and MWP compared with the TWP, but there is no significant difference between the southern part and the northern part of EAL. Second, the SST anomalies regulate the interannual variability of rainfall by modulating horizontal water vapor transport into EAL and MWP, while the IAVs of vertical velocity over EAL and MWP have little relation with SST forcing. The above results based on 12 CMIP5 models have provided a model-independent estimation of SST forcing. But a defect in the above analyses is that the climatology of SST differs between AMIP and SSTClim simulations, since AMIP simulation is forced by observed SST whereas SSTClim simulation is forced by the SST generated by coupled models. To overcome this defect, model experiments are performed with CAM4, using exactly the same climatology of SST in CTL and F SST runs, and the results are discussed in Sect. 5. 
Fig. 5 a The fraction of SST contribution to the IAV for $850 \mathrm{hPa}$ zonal water vapor transport, as estimated by the CMIP5 MMM of 1-IAV(SSTClim)/IAV(AMIP). b Regional averaged values derived from Fig. 5a, The red, blue and orange bars are for East Asian land, tropical western Pacific, and mid-latitude western Pacific, respectively. The thin black error bars show the inter-model spread measured by the standard deviation of the 12 individual models. c, d The same as $\mathbf{a}, \mathbf{b}$ but for the meridional water vapor transport at $850 \mathrm{hPa}$. e, f The same as a, $\mathbf{b}$ but for the vertical velocity at $500 \mathrm{hPa}$ (a)

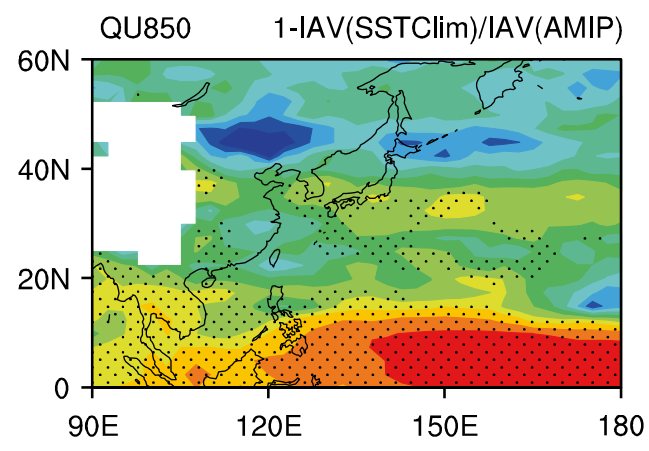

(c)

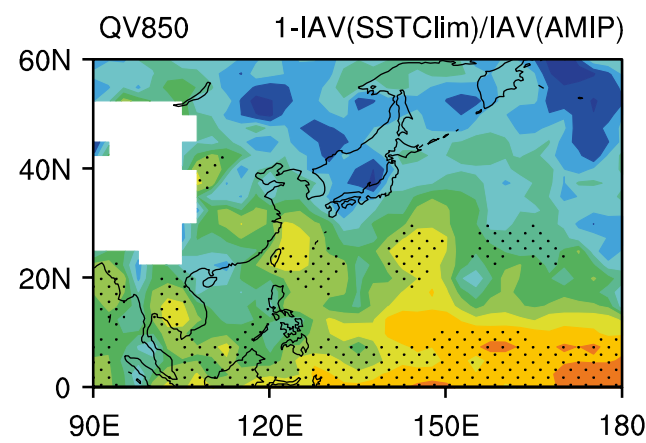

(e)

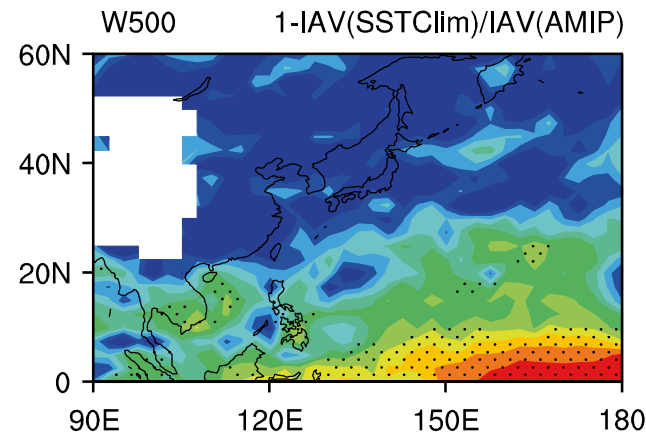

(b)

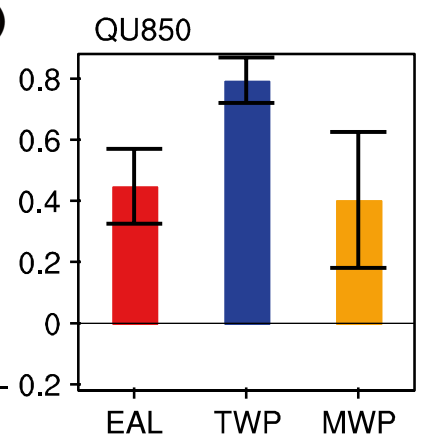

(d)

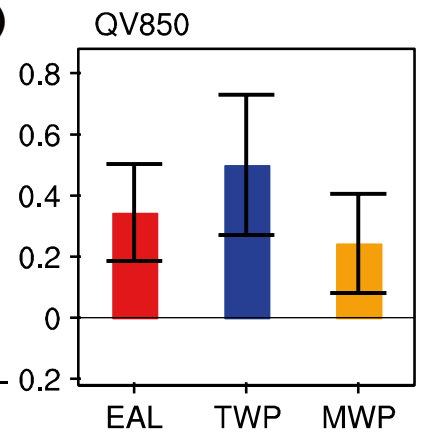

(f)

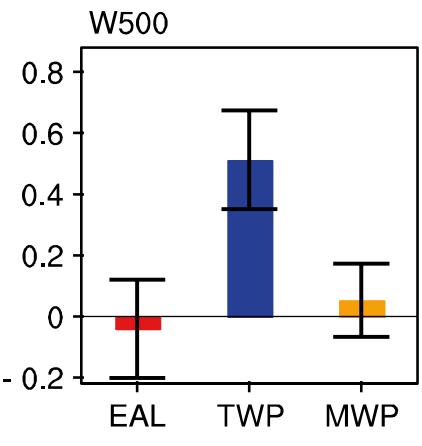

\section{$\begin{array}{llllllllll}0 & 0.1 & 0.2 & 0.3 & 0.4 & 0.5 & 0.6 & 0.7 & 0.8 & 0.9\end{array}$}

\section{SST contribution estimated by CAM4 experiments}

Figure 6 shows the spatial pattern of 1-IAV(F_SST)/ $\mathrm{IAV}(\mathrm{CTL})$ for precipitation, $850 \mathrm{hPa}$ water vapor transport and $500 \mathrm{hPa}$ vertical motion in CAM4 experiments. The spatial pattern is noisier than the MMM of CMIP5, but it supports the major results in Sect. 4. First, the fraction of SST-contributed IAV is lower in mid-latitude than in tropics, and the difference between EAL and MWP is small (Fig. 6a-d). Second, the percentage of variance explained by SST is in general the highest for the horizontal water vapor transport (Fig. 6b, c), followed by precipitation (Fig. 6a) and the lowest for vertical velocity.

The regional averages derived from Fig. 6 are shown in Fig. 7. SST contributes $17.7,41.9$ and $7.8 \%$ to the total IAV of rainfall over EAL, TWP and MWP, respectively, which are consistent with the results obtained by CMIP5 models. Over EAL region, the regional averaged SSTcontributed fractions are 21.1 and $26.8 \%$ for the zonal and meridional water vapor transport, and $7.9 \%$ for the vertical velocity. These results based on CAM4 confirm that the SST impacts the IAV of rainfall over EAL by modulating horizontal water vapor transport, rather than by modulating the vertical velocity over EAL, consistent with the conclusion drawn based on CMIP5 models. For the MWP, the CAM4 estimated SST-contributions are slightly different from CMIP5 models, and the percentages of IAV contributed by SST are 8.1, 2.0 and $6.6 \%$ for zonal, meridional water vapor transport and vertical motion. Nevertheless, the zonal water vapor transport is still more affected by SST than vertical motion, and it may still be the major mediator connecting the IAV of MWP rainfall with SST. 
Fig. 6 a The fraction of SST contribution to the IAV of precipitation, as estimated by CAM4 experiments, i.e., 1-IAV(F_SST)/IAV(CTL). The black dotted regions indicate the difference in the IAV between F_SST and CTL experiments is significant at the $95 \%$ confidence level. b-d The same as a but for the zonal water vapor transport at $850 \mathrm{hPa}$, meridional water vapor transport at $850 \mathrm{hPa}$, and vertical velocity at $500 \mathrm{hPa}$ (a)

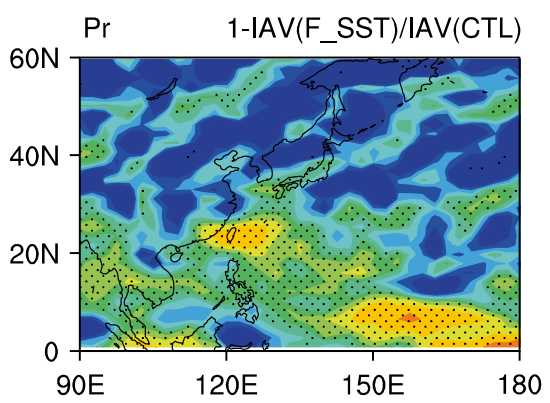

(c)

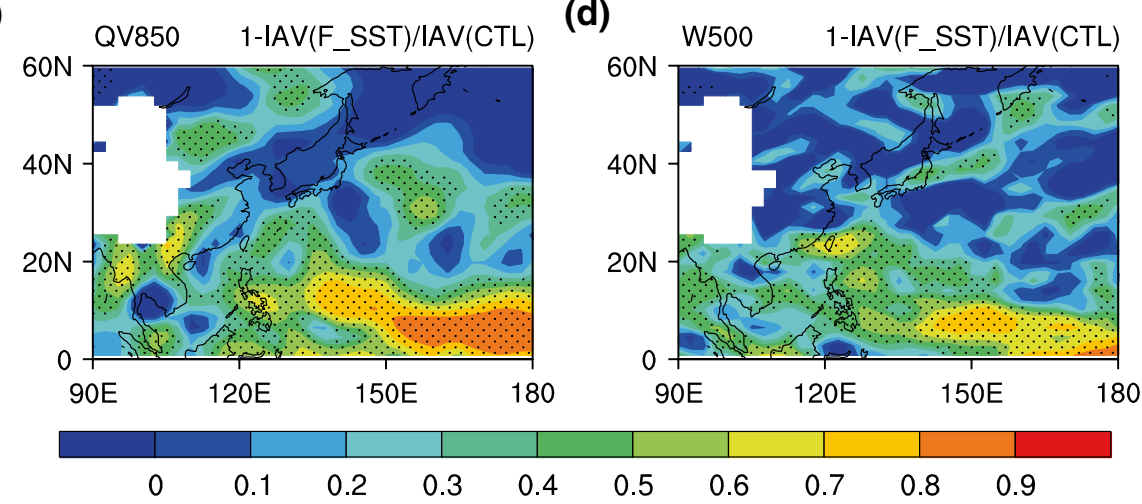

(b)

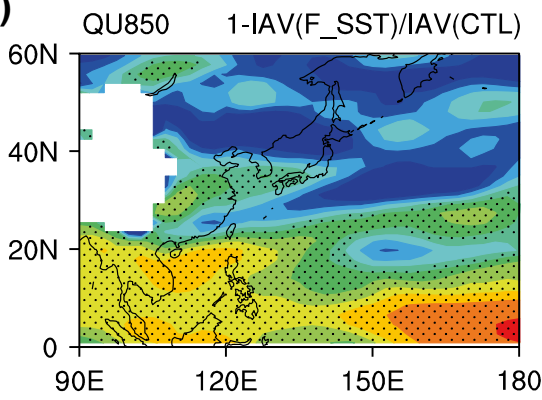

(d)

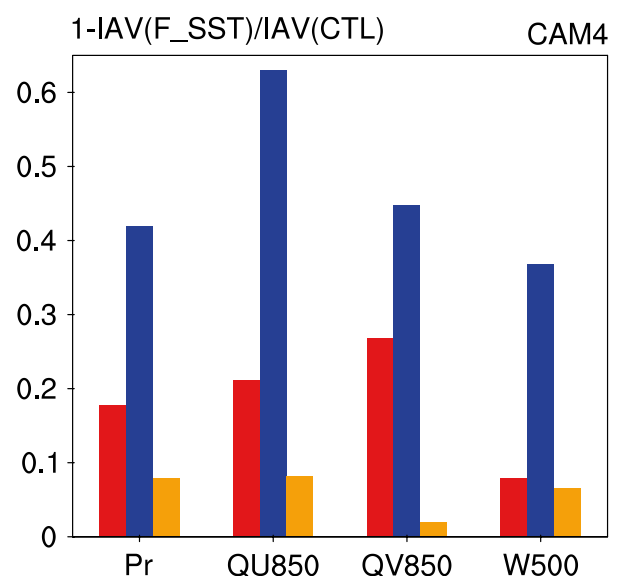

Fig. 7 Regional averaged fraction of SST contribution to precipitation (Pr), zonal water vapor transport at $850 \mathrm{hPa}$ (QU850), meridional water vapor transport at $850 \mathrm{hPa}(\mathrm{QV} 850)$ and vertical velocity at $500 \mathrm{hPa}$ (W500), as derived from the regional averages in Fig. 6. The red, blue and orange bars are for East Asian land, tropical western Pacific, and mid-latitude western Pacific, respectively, similar as in Fig. 2

Given the consistent results shown by CMIP5 models and CAM4 simulations, a quantitative conclusion can be drawn on the contribution of SST to precipitation (Fig. 8), under the assumption of independency between SST forced variability and Non-SST induced variability. The contribution of SST forcing to the IAV of summer rainfall over EAL is about $18.4 \%$ in CMIP5 MMM, with an inter-model range of $0-38 \%$. This value is estimated to be $17.7 \%$ by

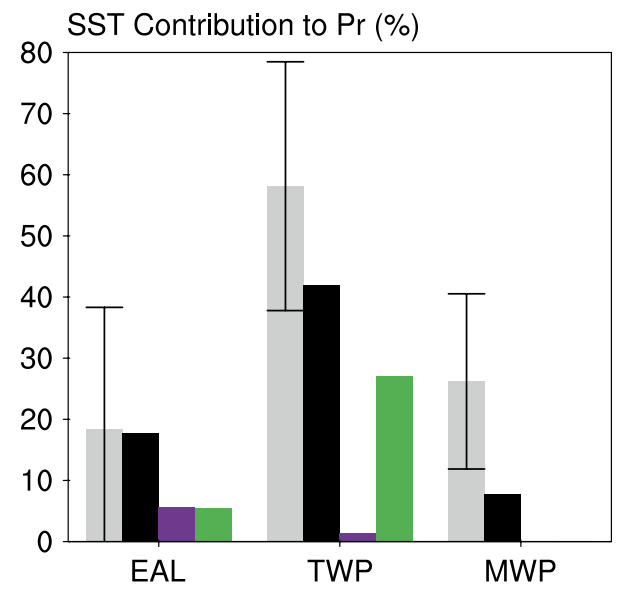

Fig. 8 Percentages of SST contribution to the IAV of precipitation for East Asian land (EAL), tropical western Pacific (TWP) and mid-latitude western Pacific (MWP), respectively. Gray bars indicate the CMIP5 multi-model median for 1-IAV(SSTClim)/IAV(AMIP), with the inter-model standard deviation denoted as the "I" type thin black bar. Thick black bars indicate CAM4 estimated 1-IAV(F_SST)/ IAV(CTL). Purple and green bars indicate the CAM4 estimated fractions of SST contribution from tropical Indian Ocean and tropical Pacific Ocean, i.e., 1-IAV(F_TIO)/IAV(CTL) and 1-IAV(F_TPO)/ $\operatorname{IAV}(\mathrm{CTL})$

CAM4. Our results are consistent with a previous study which indicated a range of 15-20\% for the southern part of East Asia (Wang et al. 2015).

As a comparison to EAL, the estimations for TWP and MWP are also shown in Fig. 8. The SST contribution to the IAV of rainfall over TWP is 58.1 and $41.9 \%$ as estimated 
by MMM of CMIP5 models and CAM4, respectively. The SST contribution to the IAV of rainfall over MWP is $26.2 \%$ as estimated by MMM of CMIP5 models, but an estimation of $7.8 \%$ is shown by CAM4. Although in-consistent values are obtained for MWP, it is still evident that the percentage of SST contribution to the IAV of rainfall over MWP is much lower than TWP but comparable to EAL.

The relative contributions of TIO and TPO SST variabilities to the IAV of summer rainfall are also evaluated in Fig. 8, which are estimated as 1-IAV(F_TIO)/IAV(CTL) and 1-IAV(F_TPO)/IAV(CTL) based on CAM4 experiments. For EAL region, $5.7 \%$ of the IAV is contributed by TIO SST and $5.5 \%$ of the IAV is contributed by TPO, consistent with Wu et al. (2003) which argued that ENSO contributes to about $4 \%$ of the East Asian summer rainfall. For TWP region, TIO contribution is $1.4 \%$, whereas TPO contribution is $27.1 \%$, suggesting the importance of local SST than the remote SST forcing. For both EAL and TWP, the sums of the contributions from TIO and TPO are smaller than the contribution of global SST (comparing the sum of purple and green bars with the black bars in Fig. 8). However, the contributions from TIO and TPO are estimated to be -4.7 and $-5.0 \%$ for the IAV of MWP rainfall. Besides chaotic factors, another possible cause for the negative values is that the interannual variability of WNP rainfall is determined by other oceanic region, e.g., local SST over subtropical WNP (Chung et al. 2011; Wang et al. 2013; He and Zhou 2014), and the remote forcing from TIO and TPO tend to offset the local SST-forced variability of MWP rainfall. In the F_TIO and F_TPO simulations, the negative contributions from TIO and TPO are absent, and the IAV of MWP rainfall would increase.

\section{Conclusion and discussion}

Based on the AMIP and SSTClim simulations of 12 CMIP5 models, the percentage of SST contribution to the interannual variability of summer rainfall over East Asian land is investigated, in comparison with tropical western Pacific and mid-latitude western Pacific. Additional model experiments are done using CAM4 to corroborate the robustness of the results, and to evaluate the relative contributions from TIO and TPO. The main conclusions are summarized as follows:

1. The contribution of SST forcing to the interannual variability of summer rainfall is about $18 \%$ over East Asian land regions, which is quantitatively agreed by MMM of CMIP5 models and CAM4 experiments. The percentage of SST contribution decreases sharply from south to north along the southern coast of East Asia.
No substantial difference is seen in the percentage of SST contribution between the southern part and the northern part of East Asia. The magnitude SST contribution to seasonal rainfall over East Asian land is much smaller than the tropical western Pacific, but is comparable to the mid-latitude western Pacific.

2. It is the horizontal water vapor transport, rather than the vertical velocity over EAL, which connects the interannual rainfall variability over EAL with the SST forcing. As agreed by CMIP5 models and CAM4 experiments, horizontal water vapor transport is more affected by SST than vertical velocity, and it may probably play a role as a mediator linking SST anomaly with rainfall anomaly in East Asian land. The IAV of vertical motion over East Asian land and mid-latitude western Pacific has little relation to the interannual SST variability, suggesting it is primarily controlled by the atmospheric internal dynamics.

3. By comparing the simulations with fixed TIO SST and fixed TPO SST, the relative importance of TIO SST and TPO SST to East Asian summer rainfall variability is investigated. It is shown that TIO contributes $5.7 \%$ of the total rainfall IAV over East Asian land, while TPO contributes $5.5 \%$. In brief, the contributions from these two ocean sectors to the interannual rainfall variability over East Asian land are comparable with each other.

In addition to observational uncertainty in the mean state of rainfall (Collins et al. 2013; He and Zhou 2015), great observational uncertainty between GPCP and CMAP is seen in the IAV of rainfall, especially over the tropical western Pacific Ocean. The Multi-model median of IAV is close to the CMAP data, but higher than the GPCP data. Therefore, great effort should be devoted to reduce the observational uncertainty of precipitation, in terms of both mean state and its variability.

The comparison between AMIP simulation with SSTClim simulation in this paper is conducted under the assumption that the atmospheric internal variability is independent on the mean state of SST, since the mean state of SST in SSTClim simulation is slightly different from that of the AMIP simulation. We recommend an additional model experiment could be done in the next generation of CMIP, by forcing AGCMs with observed SST climatology, which exactly equals the SST climatology in AMIP experiment. This experiment could help separating the SST forced phenomenon from the atmospheric internal dynamics.

Acknowledgments We wish to thank the PCMDI which provides model data and NOAA which provides observational data. We also wish to thank Dr Zhenyu Han (In CMA) and Dr Jiawen Zhu (in IAP) for useful discussions in performing the analyses and performing CAM4 experiments. This work was jointly supported by National 
Basic Research Program of China (2014CB953901), China Meteorological Administration Special Public Welfare Research Fund (GYHY201406001) and National Natural Science Foundation of China (41375095, 41575043, 41505067, 41330423, and 41205069).

Open Access This article is distributed under the terms of the Creative Commons Attribution 4.0 International License (http://creativecommons.org/licenses/by/4.0/), which permits unrestricted use, distribution, and reproduction in any medium, provided you give appropriate credit to the original author(s) and the source, provide a link to the Creative Commons license, and indicate if changes were made.

\section{References}

Adler RF, Huffman GJ, Chang A, Ferraro R, Xie PP, Janowiak J, Rudolf B, Schneider U, Curtis S, Bolvin D, Gruber A, Susskind J, Arkin P, Nelkin E (2003) The version-2 global precipitation climatology project (GPCP) monthly precipitation analysis (1979-present). J Hydrometeorol 4(6):1147-1167. doi:10.1175/1525-7541(2003)004<1147:tvgpcp >2.0.co;2

Cao J, Lu RY, Hu JM, Wang H (2013) Spring Indian Ocean-western Pacific SST contrast and the East Asian summer rainfall anomaly. Adv Atmos Sci 30(6):1560-1568. doi:10.1007/ s00376-013-2298-6

Chang CP, Zhang YS, Li T (2000) Interannual and interdecadal variations of the East Asian summer monsoon and tropical Pacific SSTs. Part I: Roles of the subtropical ridge. J Clim 13(24):4310 4325. doi:10.1175/1520-0442(2000)013<4310:iaivot>2.0.co;2

Chung P-H, Sui C-H, Li T (2011) Interannual relationships between the tropical sea surface temperature and summertime subtropical anticyclone over the western North Pacific. J Geophys ResAtmos 116:D13111. doi:10.1029/2010jd015554

Collins M, AchutaRao K, Ashok K, Bhandari S, Mitra AK, Prakash S, Srivastava R, Turner A (2013) Observational challenges in evaluating climate models. Nat Clim Change 3:940-941

Conil S, Douville H, Tyteca S (2007) The relative influence of soil moisture and SST in climate predictability explored within ensembles of AMIP type experiments. Clim Dyn 28(2-3):125145. doi:10.1007/s00382-006-0172-2

Duan A, Wu G, Liu Y, Ma Y, Zhao P (2012) Weather and climate effects of the Tibetan Plateau. Adv Atmos Sci 29(5):978-992. doi:10.1007/s00376-012-1220-y

Fan K, Xu Z, Tian B (2014) Has the intensity of the interannual variability in summer rainfall over South China remarkably increased? Meteorol Atmos Phys 124(1-2):23-32. doi:10.1007/ s00703-013-0301-5

Ferguson IM, Dracup JA, Duffy PB, Pegion P, Schubert S (2010) Influence of SST forcing on stochastic characteristics of simulated precipitation and drought. J Hydrometeorol 11(3):754-769. doi:10.1175/2009jhm1132.1

Gleckler PJ, Taylor KE, Doutriaux C (2008) Performance metrics for climate models. J Geophys Res Atmos 113(D6):D06104. doi:10. 1029/2007jd008972

He C, Zhou T (2014) The two interannual variability modes of the Western North Pacific Subtropical High simulated by 28 CMIP5-AMIP models. Clim Dyn 43(9-10):2455-2469. doi:10.1007/s00382-014-2068-x

He C, Zhou T (2015) Responses of the Western North Pacific Subtropical High to global warming under RCP4.5 and RCP8.5 scenarios projected by 33 CMIP5 models: the dominance of tropical Indian Ocean-Tropical Western Pacific SST gradient. J Clim 28(1):365-380. doi:10.1175/jcli-d-13-00494.1
Hurrell JW, Hack JJ, Shea D, Caron JM, Rosinski J (2008) A new sea surface temperature and sea ice boundary dataset for the Community Atmosphere Model. J Clim 21(19):5145-5153. doi:10.1 175/2008jcli2292.1

Johnson NC, Xie S-P (2010) Changes in the sea surface temperature threshold for tropical convection. Nat Geosci 3(12):842-845. doi:10.1038/ngeo1008

Kosaka Y, Chowdary JS, Xie SP, Min YM, Lee JY (2012) Limitations of seasonal predictability for summer climate over East Asia and the Northwestern Pacific. J Clim 25(21):7574-7589. doi:10.1175/jcli-d-12-00009.-1

Kosaka Y, Xie S-P, Lau N-C, Vecchi GA (2013) Origin of seasonal predictability for summer climate over the Northwestern Pacific. Proc Natl Acad Sci 110(19):7574-7579. doi:10.1073/ pnas. 1215582110

Koster RD, Suarez MJ, Heiser M (2000) Variance and predictability of precipitation at seasonal-to-interannual timescales. J Hydrometeorol 1(1):26-46. doi:10.1175/1525-7541(2000)001<0026:vapop a>2.0.co;2

Kumar A, Hoerling MP (1995) Prospects and limitations of seasonal atmospheric GCM predictions. B Am Meteorol Soc 76(3):335-345. doi:10.1175/1520-0477(1995)076<0335:palos a $2.0 . \operatorname{co} ; 2$

Li SL, Lu J, Huang G, Hu KM (2008) Tropical Indian Ocean Basin warming and East Asian summer monsoon: a multiple AGCM study. J Clim 21(22):6080-6088. doi:10.1175/2008jcli2433.1

Li XZ, Wen ZP, Zhou W, Wang DX (2012) Atmospheric water vapor transport associated with two decadal rainfall shifts over East China. J Meteorol Soc Jpn 90(5):587-602. doi:10.2151/ jmsj.2012-501

Li X, Zhou W, Chen D, Li C, Song J (2014) Water vapor transport and moisture budget over Eastern China: remote forcing from the two types of El Niño. J Clim 27(23):8778-8792. doi:10.1175/ jcli-d-14-00049.1

Li Z, Zhou T, Chen H, Ni D, Zhang R-H (2015) Modelling the effect of soil moisture variability on summer precipitation variability over East Asia. Int J Climatol 35(6):879-887. doi:10.1002/ joc. 4023

Lin AL, Li CH, Gu DJ, Zheng B (2012) Variation and causes of persistent drought events in Guangdong Province. J Trop Meteorol 18(1):54-64. doi:10.3969/j.issn.1006-8775.2012.01.006

Lu R, Fu Y (2010) Intensification of East Asian summer rainfall interannual variability in the twenty-first century simulated by 12 CMIP3 coupled models. J Clim 23(12):3316-3331. doi:10.117 5/2009jcli3130.1

Lu R, Li Y, Dong B (2006) External and internal summer atmospheric variability in the Western North Pacific and East Asia. J Meteorol Soc Jpn Ser II 84(3):447-462. doi:10.2151/jmsj.84.447

Neale RB, Richter JH, Conley AJ, Park S, Lauritzen PH, Gettelman A, Williamson DL, Rasch PJ, Vavrus SJ, Taylor MA, Collins WD, Zhang MH, Lin S-J (2010) Description of the NCAR Community Atmosphere Model (CAM4.0), USA

Song F, Zhou T, Wang L (2013) Two modes of the silk road pattern and their interannual variability simulated by LASG/IAP AGCM SAMIL2.0. Adv Atmos Sci 30(3):908-921. doi:10.1007/ s00376-012-2145-1

Stevenson S, Timmermann A, Chikamoto Y, Langford S, DiNezio P (2015) Stochastically generated North American megadroughts. J Clim 28(5):1865-1880. doi:10.1175/jcli-d-13-00689.1

Sun S, Wang G (2014) Climate variability attributable to terrestrial and oceanic forcing in the NCAR CAM3-CLM3 Models. Clim Dyn 42(7-8):2067-2078. doi:10.1007/s00382-013-1913-7

Taylor KE, Stouffer RJ, Meehl GA (2012) An overview of CMIP5 and the experiment design. B Am Meteorol Soc 93(4):485-498. doi:10.1175/bams-d-11-00094.1 
Wang HJ, Chen HP (2012) Climate control for southeastern China moisture and precipitation: Indian or East Asian monsoon? J Geophys Res Atmos 117:D12109. doi:10.1029/2012jd017734

Wang B, Xiang B, Lee J-Y (2013) Subtropical High predictability establishes a promising way for monsoon and tropical storm predictions. Proc Natl Acad Sci 110(8):2718-2722. doi:10.1073/ pnas. 1214626110

Wang B, Lee J-Y, Xiang B (2015) Asian summer monsoon rainfall predictability: a predictable mode analysis. Clim Dyn 44(12):61-74. doi:10.1007/s00382-014-2218-1

Wu R, Hu Z-Z, Kirtman BP (2003) Evolution of ENSO-related rainfall anomalies in East Asia. J Clim 16(22):3742-3758. doi:10.1175/1520-0442(2003)016<3742:eoerai $>2.0 . c 0 ; 2$

Wu Z, Wang B, Li J, Jin F-F (2009) An empirical seasonal prediction model of the east Asian summer monsoon using ENSO and NAO. J Geophys Res Atmos 114:D18120. doi:10.1029/200 9jd011733

Wu B, Li T, Zhou TJ (2010) Relative contributions of the Indian Ocean and local SST anomalies to the maintenance of the Western North Pacific Anomalous Anticyclone during the El Nino decaying summer. J Clim 23(11):2974-2986. doi:10.1175/2010 jcli3300.1

Xiang B, Wang B, Yu W, Xu S (2013) How can anomalous western North Pacific Subtropical High intensify in late summer? Geophys Res Lett 40(10):2349-2354. doi:10.1002/grl.50431

Xie PP, Arkin PA (1997) Global precipitation: a 17-year monthly analysis based on gauge observations, satellite estimates, and numerical model outputs. B Am Meteorol Soc 78(11):25392558. doi:10.1175/1520-0477(1997)078<2539:gpayma $>2.0 . c 0 ; 2$
Xie SP, Hu KM, Hafner J, Tokinaga H, Du Y, Huang G, Sampe T (2009) Indian Ocean capacitor effect on Indo-Western Pacific climate during the summer following El Nino. J Clim 22(3):730 747. doi:10.1175/2008jcli2544.1

Yang S, Zhang Z, Kousky VE, Higgins RW, Yoo S-H, Liang J, Fan Y (2008) Simulations and seasonal prediction of the Asian summer monsoon in the NCEP climate forecast system. J Clim 21(15):3755-3775. doi:10.1175/2008jcli1961.1

Yang D, Tang Y, Zhang Y, Yang X (2012) Information-based potential predictability of the Asian summer monsoon in a coupled model. J Geophys Res Atmos 117(D3):D03119. doi:10.1029/20 $11 \mathrm{jd} 016775$

Yim S-Y, Wang B, Xing W (2014) Prediction of early summer rainfall over South China by a physical-empirical model. Clim Dyn 43(7-8):1883-1891. doi:10.1007/s00382-013-2014-3

Zhang R (2001) Relations of water vapor transport from Indian monsoon with that over East Asia and the summer rainfall in China. Adv Atmos Sci 18(5):1005-1017

Zhang J, Wu L, Dong W (2011) Land-atmosphere coupling and summer climate variability over East Asia. J Geophys Res Atmos 116(D5):D05117. doi:10.1029/2010jd014714

Zhou TJ, Yu RC (2005) Atmospheric water vapor transport associated with typical anomalous summer rainfall patterns in China. J Geophys Res Atmos 110:D08104. doi:10.1029/2004jd005413

Zuo Z, Yang S, Hu Z-Z, Zhang R, Wang W, Huang B, Wang F (2013) Predictable patterns and predictive skills of monsoon precipitation in Northern Hemisphere summer in NCEP CFSv2 reforecasts. Clim Dyn 40(11-12):3071-3088. doi:10.1007/ s00382-013-1772-2 